\title{
Various aspects of research of the SI engine with an additional expansion process
}

\author{
$\operatorname{Marcin} \mathrm{Noga}^{1, *}$ \\ ${ }^{1}$ Cracow University of Technology, Institute of Automobiles and Internal Combustion Engines, al. Jana Pawla II 37, 31-864 Krakow, \\ Poland
}

\begin{abstract}
The paper presents an analysis of the results of the both experimental results and theoretical works on the SI engine with additional expansion of exhaust gases, also known as five-stroke engine. The engine like this was constructed at Cracow University of Technology as a retrofitted in-line four cylinder engine in which outer cylinders (1st and 4th) work as fired cylinders and inner cylinders (2nd and 3rd) work as volume for the additional expansion. The aim of development of such an engine is to gain higher energy recovery ratio of the combusted fuel through the second expansion of exhaust in a separate cylinder. The operating parameters of the engine in various versions were analyzed: as naturally aspirated, supercharged using a turbocharger with a waste-gate valve and a turbocharger with variable nozzle turbine. Selected results of the indicating measurements of the engine with special emphasis on the indicated thermal efficiency were presented. The results pointed out the directions of further optimization of the engine. These results are all the more important, because according to the author's knowledge, the research on the real object of this type are carried out in only one science center in the world besides Cracow University of Technology.
\end{abstract}

\section{Introduction}

The use of internal combustion engines to drive vehicles is inevitably associated with emissions of toxic exhaust gas and carbon dioxide into the atmosphere. The number of motor vehicles on the roads of the world is growing year by year. In order to reduce pollution of the natural environment, more stringent emission limits for toxic gases and $\mathrm{CO}_{2}$ emissions are introduced. The vehicle approval testing procedures are changed to match the actual road conditions [1, 2]. However, despite the introduction of advanced technical solutions for the engines themselves as well as the exhaust aftertreatment systems, it is not possible to completely eliminate the problem of emissions from the powertrains with combustion engines. Consequently, interest in electric vehicles has increased over the past 20 years [3]. The pure electric drive for vehicles has the advantage that the vehicle does not emit toxic components or $\mathrm{CO}_{2}$ in the area where it is used. Some negative connotations are connected with the way of generating electricity in a given area [4]. In any case, it is true that the use of electric cars in crowded city centers will significantly improve the quality of the air there.

However, electric drives for road vehicles encounter many problems in their development. The most important problem is the extremely limited capacity of electric energy storage system using contemporary batteries, which in turn causes very significant problems in obtaining a range acceptable to the user while maintaining a reasonable price for such a vehicle [5]. The next constraint in development is the long battery charging time and the troubles of developing a common standard of charging device for all electric car manufacturers [6]. Such a state of affairs makes that a reasonable solution for the coming years is to improve and further disseminate the various hybrid drive systems for road vehicles [7]. First of all the use of a hybrid system gives the ability to reduce fuel consumption through energy recovery during braking and enables the engine to operate in a limited area of the operational map in which it is highly efficient. On the one hand, electrical systems are developed. Innovative high-performance electric motors are emerging, innovative electronic solutions such as SiC-based transistors are used in inverters and voltage converters. On the other hand, internal combustion engines for hybrid drive systems are also subject to continuous improvement [8].

\section{Engines with an extended expansion process - the background}

As with all automotive combustion engines, also for engines for hybrid vehicles, the development is now primarily driven by emission reduction and fuel consumption considerations. The engines of hybrid drive systems work in slightly different regime than in conventional propulsion systems. This causes that they can be optimized for a narrower area of the work map, to

* Corresponding author: noga@pk.edu.pl 
work mainly in this optimized area [9]. One of the ways to make better use of the part of energy of the burned fuel that is lost in the exhaust system in a normal engine is to use an increased expansion ratio of the exhaust gases in relation to the compression ratio [10-12]. A comparison of the thermodynamic cycle of the classical SI engine and the cycle with expansion of exhaust gases to the ambient pressure is presented in a Figure 1.

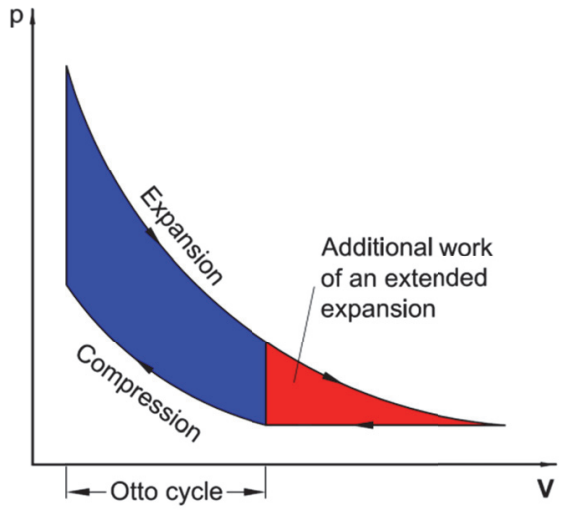

Fig. 1. Thermodynamic cycle with an additional expansion process.

As it is shown in the figure above, the cycle with extended expansion of the charge with the same amount of heat supplied to the working medium offers an additional portion of useful work, which contributes to a significant increase in the efficiency of the engine working according to this principle $[13,14]$.

The first attempts to implement this idea into a heat engine include the James Atkinson engine [15], in which the intake and compression stroke were shorter than the power (expansion) stroke and exhaust stroke. Miller presented a different approach for a 4-stroke supercharged engine [16]. He proposed closing the intake valve before the end of the intake stroke, which, in addition to cooling the expanding cylinder charge, reduced the effective compression ratio. A similar effect is achieved by closing the intake valve far after the BDC, what was used in Japanese car engines as early as the 90 s of the 20th century [17]. In this type of engine, the expansion of the charge occurs as in the classical engine, which results, with the shortened effective part of the compression stroke, in a significant increase in the expansion ratio over the compression ratio. In recent years, the popularity of engines realizing Atkinson/ Miller cycle at least in part of their map has increased [18]. Research and development works on engines with increased expansion ratio are also carried out in several scientific centers in Poland [19-21].

However, it should be noted that increasing the efficiency of internal combustion engines in this way is not free of disadvantages. The first one is the reduced maximum performance [22] resulting from reduced volumetric efficiency. Another is pumping back the fuelair mixture to the intake manifold at the start of the compression stroke with the intake valve open, which is not a loss-free process [23].
A slightly different approach to the concept of extended charge expansion was presented by Gerhard Schmitz [24] in his engine, which proposed that additional (second) expansion of exhaust gas occurs in a separate low pressure cylinder with a volume significantly higher than the volume of the fired cylinder in which a four-stroke cycle is performed. The engine with additional expansion of the exhaust in a separate cylinder has the advantage that the design parameters of the two cylinders can be optimized for their functions independently of each other. This mainly concerns the compression ratio of the working cylinder and the volume of additional expansion of the working medium. The first working model of this engine was built by Ilmor Engineering and named as a five-stroke engine due to the fifth stroke of an additional expansion added to the classic four-stroke cycle. Gerhard Schmitz's five-stroke engine has two working cylinders with $360 \mathrm{deg}$ CA phase shift of the operation. Exhaust gases from these cylinders feeds alternately the additional expansion cylinder placed in the middle of engine, which in this situation operates in a two-stroke mode. The five-stroke engine design is shown in Figure 2.

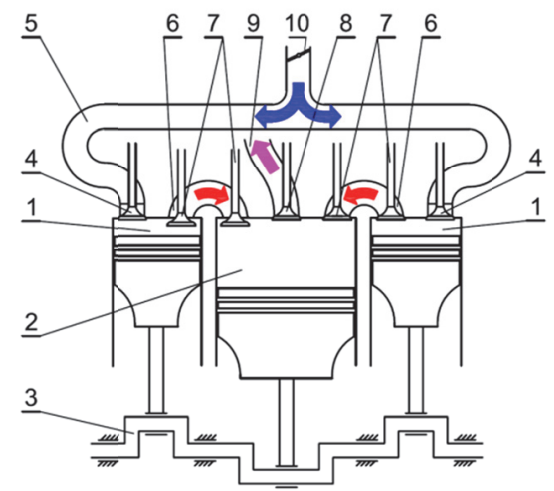

Fig. 2. Scheme of the three cylinder five-stroke engine; 1 - fired cylinders, 2 - additional expansion cylinder,

3 - crankshaft, 4 - intake valves, 5 - intake manifold,

6 - transfer port, 7 - transfer port valves, 8 - exhaust valve,

9 - exhaust port, 10 - throttle.

Currently, the inventor of the five-stroke engine develops his concept in a team working on the use of this engine for a hybrid powertrain $[25,26]$. Generally, the issue of the five-stroke engine raises a lot of interest among researchers from all over the world. This is evidenced by publications on various modelling and simulations of the 5-stroke engine [27-31], however, the results of the experimental work of such an engine were presented by the team whose member is the originator of the engine $[25,26]$ as well as by the author of this paper $[10,13,32,33]$.

\section{The five-stroke engine developed at Cracow University of Technology}

In 2011-2013, at the Cracow University of Technology (CUT) a research project N N509 559040 funded by the National Science Center of Poland was carried out. 
Professor Bronisław Sendyka was head of the project and the author of this article was a principal investigator. Within this project, an expanded-expansion engine was developed based on an in-line four cylinder engine. The developed engine has two fired cylinders (No. 1 and No. 4), while the central cylinders (No. 2 and No. 4) are connected by an internal port in the cylinder head and form a volume of additional expansion of working medium. The project required significant modifications to the cylinder head ports and designing of new camshafts and intake and exhaust manifolds. As shown in Figure 3 the exhaust gases from the cylinders No. 1 and No. 4. are now returned to the cylinders respectively No. 2 and No. 3, where they undergo an additional expansion process. Only after this process exhaust gases leave the engine. This causes that the camshaft, which originally controlled only the intake valves of the engine, now controls the intake valves of the fired cylinders 1 and 4 and the exhaust valves of the cylinders of an additional expansion process No. 2 and No. 3. The camshaft which was an exhaust camshaft for the 4-stroke engine now controls the valves of the transfer ports between cylinders 1 and 2 as well as 4 and 3. It should also be noted that all engine exhaust valves open at the same time once for each rotation of the crankshaft (2stroke mode of work of the additional expansion cylinders).

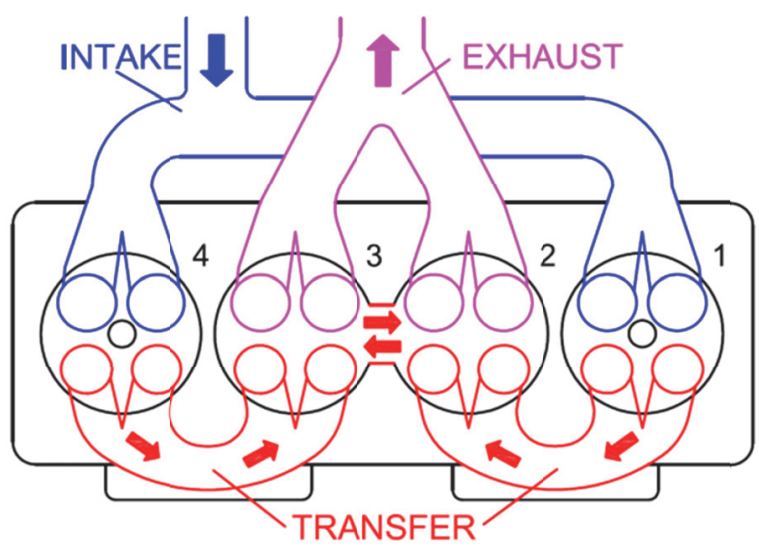

Fig. 3. Scheme of a cylinder head flow of the five-stroke engine developed at Cracow University of Technology.

After the preliminary tests, where the engine worked as a naturally aspirated engine, it was equipped with a turbocharger. Experimental research of the engine equipped with a turbocharger with a boost pressure controlled by a waste-gate valve (WG) upstream the turbine, followed with a turbocharger with a variablenozzle turbine (VNT) were carried out. Selected results of this work will be presented later in the article. The specifications of the five-stroke engine developed at CUT are presented in a Table 1.

Control of the engine work is based on a programmable engine management system that allows real-time settings to be changed. In addition, the engine has a direct injection system. Fuel injection pressure during tests, the results of which are presented here, was set at $7 \mathrm{MPa}$. The engine was supplied with a mixture of stoichiometric composition (rel. AFR $=1.0$ ) with a wideband exhaust oxygen sensor in a feedback loop. This was due to the desire to match the engine to the requirements of the classic three-way catalytic converter.

Table 1. Technical data of the five-stroke engine developed at CUT.

\begin{tabular}{|l|c|}
\hline \multicolumn{1}{|c|}{ Parameter } & Value \\
\hline $\begin{array}{l}\text { Number of cylinders and } \\
\text { arrangement }\end{array}$ & $\begin{array}{c}4 \text { in-line, 2 fired and 2 } \\
\text { for an additional } \\
\text { expansion }\end{array}$ \\
\hline Bore & $82.5 \mathrm{~mm}$ \\
\hline Stroke & $92.8 \mathrm{~mm}$ \\
\hline Displacement of a fired cylinder & $496 \mathrm{~cm}^{3}$ each \\
\hline $\begin{array}{l}\text { Displacement of additional } \\
\text { expansion cylinders }\end{array}$ & $992 \mathrm{~cm}^{3}$ both \\
\hline Compression ratio & 4 per cylinder \\
\hline No. of valves & $\begin{array}{c}\text { KP39 (with WG), } \\
\text { BV35 (with VNT) }\end{array}$ \\
\hline Turbocharger type & AEM EMS 30-1010 \\
\hline Control system model & Direct injection \\
\hline Injection method & Denso 131000-1041 \\
\hline Injector driver & pressure relief valve \\
\hline $\begin{array}{l}\text { Control method of high-pressure: } \\
\text { of fuel }\end{array}$ &
\end{tabular}

A valve timing of the test engine are listed in Table 2. The intake valve timing of the fired cylinders is fixed and correspond to the center position of the camshaft in the base engine, which originally had a system of variable valve timing. The exhaust valve timing of the fired cylinders and the additional expansion cylinders are the same as in the base engine. The intake valves of the additional expansion cylinders work synchronously with the exhaust valves of the adjacent fired cylinders, i.e. 1 together with 2 and 4 together with 3.

Table 2. Valve timing of the engine with an additional expansion process developed at CUT.

\begin{tabular}{|c|c|c|}
\hline Valve timing & Fired cylinders & $\begin{array}{c}\text { Additional expansion } \\
\text { cylinders }\end{array}$ \\
\hline EVO & $28^{\circ} \mathrm{BBDC}$ & $28^{\circ} \mathrm{BBDC}$ \\
\hline EVC & $8^{\circ} \mathrm{BTDC}$ & $8^{\circ} \mathrm{BTDC}$ \\
\hline IVO & $7^{\circ} \mathrm{ATDC}$ & $28^{\circ} \mathrm{BTDC}$ \\
\hline IVC & $17^{\circ} \mathrm{ABDC}$ & $8^{\circ} \mathrm{BBDC}$ \\
\hline
\end{tabular}

The presented valve timing is given in accordance with the manufacturer's base engine guidelines. This means that the opening and cllosing angles of the valves are given for the valve lift of $1.0 \mathrm{~mm}$. The engine tests was carried out in the Laboratory of Combustion Engines at Cracow University of Technology. The test stand is equipped with an electronically controlled Eddycurrent dynamometer, with a system for measuring and recording engine operating parameters, a gravimetric 
fuel flowmeter and an exhaust gas analyzer. The general view of the 5-stroke engine test bench is shown in Fig. 4.

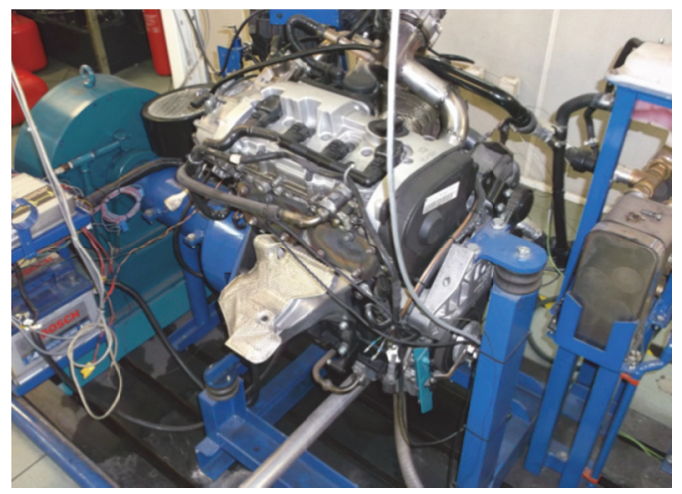

Fig. 4. General view of a test-stand of the engine with additional expansion process developed at CUT.

\section{Selected research aspects of the engine with an additional expansion process}

\subsection{Thermodynamic cycle of the engine with an additional expansion process}

For initial assessment of the potential of improving the efficiency the theoretical cycle for the engine with an additional expansion of exhaust gas and the expansion ratio higher twice than the compression ratio has been developed $[10,13]$. This is the cycle based on the Otto cycle, but with an extended expansion process to a volume equal to the total volume of the two engine cylinders. For the analysis air as an ideal gas was used, which is the working medium of the cycle. Due to the simplification of the analysis, the cycle is carried out in one working volume, and the pressure drop at the opening of the valves of transfer ports connecting the fired cylinder to the additional expansion cylinder is not taken into account. In the aforementioned works, the influence of selected parameters of the cycle on the obtained thermal efficiency of the cycle was analyzed. It is important to point out that, unlike the Otto cycle, the thermal efficiency of the cycle with an additional expansion depends on the amount of heat supplied to the cycle. Figure 5 shows the theoretical cycle of the engine with an additional expansion of exhaust gases developed at CUT.

If the amount of heat supplied to the cycle is high enough (process 2-3), the expansion process ends up above the ambient pressure - point $4_{5 \mathrm{~s}}$. Then the process of heat rejection at a constant volume occurs - process $4{ }_{5 \mathrm{~s}}-5_{5 \mathrm{~s}}$ and the process of heat rejection at constant pressure of $5_{5 \mathrm{~s}}-1$. In the particular case, when the amount of heat supplied to the cycle is accordingly lower (process 2-3'), the expansion of the charge ends exactly at $5_{5 \mathrm{~s}}$, i.e. at atmospheric pressure. When the amount of heat supplied to the cycle is even smaller (process 2-3") the expansion of the working medium to the volume of $2 \times\left(V_{\text {cyl }}+V_{\text {ch }}\right)$ results in a pressure drop below the ambient pressure $p_{\text {amb }}-$ process $\left(3 "-4{ }_{5 \mathrm{~s}}\right)$. Then there is the process of additional heat supply to the cycle at constant volume (process $4 "{ }_{5 \mathrm{si}}-5_{5 \mathrm{~s}}$ ), followed by the heat rejection at a constant pressure.

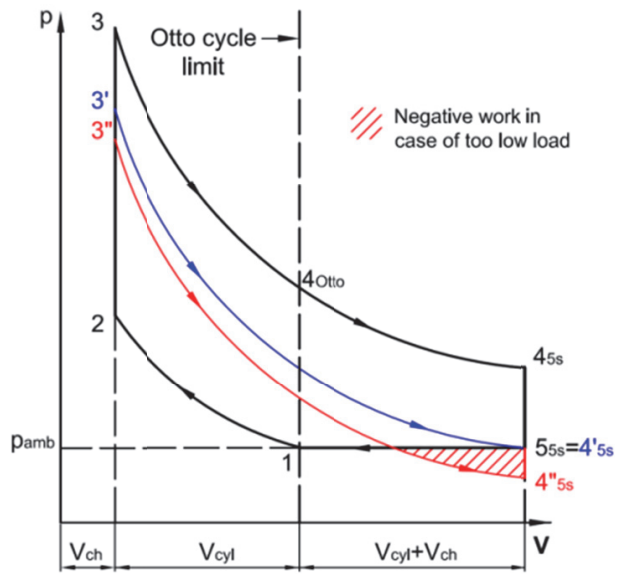

Fig. 5. Thermodynamic cycle of the engine with an additional expansion process to the volume of $2 \times\left(V_{\mathrm{cyl}}+V_{\mathrm{ch}}\right)$.

The graph shows the area of a negative work appearing at that time. The paper [13] presents the formula for the thermal efficiency of the proposed cycle:

$$
\eta_{5 s}=\frac{\alpha-1+\varepsilon_{c p}^{1-\kappa^{*}\left(2-\kappa-\alpha \cdot 2^{1-\kappa}\right)}}{\alpha-1}
$$

where:

$\eta_{5 s}$ - thermal efficiency of the proposed cycle,

$\alpha$ - heat addition pressure ratio, $\alpha=p_{3} / p_{2}$,

$\kappa$-isentropic exponent,

$\varepsilon_{c p}-$ compression ratio, $\varepsilon_{c p}=\frac{V_{1}}{V_{2}}=\frac{V_{c h}+V_{c y l}}{V_{c h}}$.

The formula (1) for calculating thermal efficiency of the cycle is valid for the amount of heat supplied to the cycle allowing to reach the pressure of the point $3^{\prime}$ and higher. Table 3 shows the dataset used for the analysis of the proposed cycle.

Table 3. Parameters of the proposed cycle used for presented analysis.

\begin{tabular}{|l|c|c|c|}
\hline \multicolumn{1}{|c|}{ Parameter } & Symbol & Unit & Value \\
\hline $\begin{array}{l}\text { Specific heat at const. } \\
\text { pressure }\end{array}$ & $c_{p}$ & {$[\mathrm{~kJ} /(\mathrm{kg} \cdot \mathrm{K})]$} & 1.005 \\
\hline $\begin{array}{l}\text { Specific heat at } \\
\text { constant volume }\end{array}$ & $c_{V}$ & {$[\mathrm{~kJ} /(\mathrm{kg} \cdot \mathrm{K})]$} & 0.718 \\
\hline Isentropic exponent & $\kappa$ & {$[-]$} & 1.4 \\
\hline $\begin{array}{l}\text { Mass of the working } \\
\text { medium }\end{array}$ & $m$ & {$[\mathrm{~kg}]$} & $0.636 \times 10^{-3}$ \\
\hline $\begin{array}{l}\text { Initial pressure } \\
\text { (ambient) }\end{array}$ & $p_{1}$ & {$[\mathrm{MPa}]$} & 0.1 \\
\hline $\begin{array}{l}\text { Initial temperature } \\
\text { (ambient) }\end{array}$ & $T_{1}$ & {$[\mathrm{~K}]$} & 300 \\
\hline Cylinder displacement & $V_{c y l}$ & {$\left[\mathrm{~m}^{3}\right]$} & $496 \times 10^{-6}$ \\
\hline $\begin{array}{l}\text { Volume of a comb. } \\
\text { chamber }\end{array}$ & $V_{c h}$ & {$\left[\mathrm{~m}^{3}\right]$} & $52.2 \times 10^{-6}$ \\
\hline Overall expansion ratio & $\varepsilon_{d c p}$ & {$[-]$} & 21 \\
\hline
\end{tabular}


The expansion ratio is exactly twice of the compression ratio $\varepsilon_{c p}$, because the final volume of working medium is equal to the displacement volume of the two cylinders and their two combustion chambers, thus the formula (2) is true:

$$
\varepsilon_{d c p}=\frac{2 \cdot\left(V_{c h}+V_{c y l}\right)}{V_{c h}}=2 \varepsilon_{c p}
$$

If one takes into account the data set from Table 3, the minimum amount of heat supplied to the cycle $Q_{H_{-} \min }^{\prime}$ allowing to reach the pressure of point $3^{\prime}$ can be determined from the set of following equations (3)-(7):

$$
\begin{gathered}
Q_{H_{-} \min }^{\prime}=m \cdot c_{V} \cdot\left(T_{3 \prime}-T_{2}\right) \\
T_{3 \prime}=T_{2} \cdot \frac{p_{3 \prime}}{p_{2}} \\
p_{3 \prime}=p_{4,5 s} \cdot\left(\frac{V_{4^{\prime} 5 s}}{V_{3^{\prime}}}\right)^{\kappa}=p_{4,5 s} \cdot\left(\varepsilon_{d c p}\right)^{\kappa} \\
T_{2}=T_{1} \cdot \frac{p_{2} \cdot V_{2}}{p_{1} \cdot V_{1}}=T_{1} \cdot \frac{p_{2}}{p_{1}} \cdot\left(\varepsilon_{c p}\right)^{-1} \\
p_{2}=p_{1} \cdot\left(\frac{V_{1}}{V_{2}}\right)^{\kappa}=p_{1} \cdot\left(\varepsilon_{c p}\right)^{\kappa}
\end{gathered}
$$

Finally, after the insertion of data and execution of the calculations, the minimum amount of heat supplied to the cycle $Q_{H_{-} \text {min }}^{\prime}$ was equal to $575.1 \mathrm{~J}$. For such a limit of the supplied heat, the heat-addition pressure ratio (or explosion ratio) $\alpha^{\prime}$ equals (8):

$$
\alpha^{\prime}=\frac{p_{3 \prime}}{p_{2}}=\frac{7.097526}{2.689460}=2.639
$$

Figure 6 shows a curve of the thermal efficiency $\eta 5 \mathrm{~s}$ of the theoretical cycle of the engine with an additional expansion of the working medium to the total volume of the two cylinders as a function of the amount of heat supplied to the $Q_{H}$ cycle. The figure also shows the thermal efficiency of the Otto cycle, which has a constant value, independent of the amount of heat supplied to the cycle.

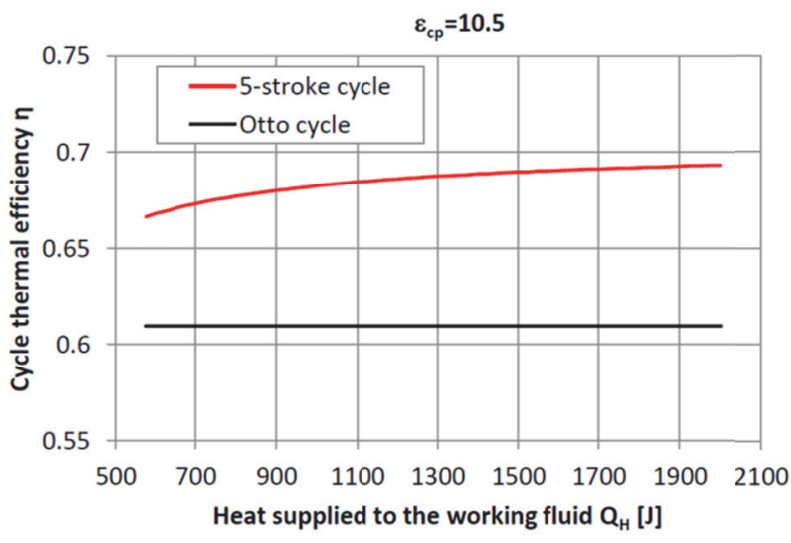

Fig. 6. Comparison of the thermal efficiency of Otto and 5 -stroke engine cycle as a function of amount of heat supplied to the working fluid.

For the data being analyzed, Otto cycle efficiency is about 0.61 and is constant, while the efficiency of the cycle of the engine with an additional expansion process increases with the increase in the amount of heat supplied to the working medlium $Q_{H}$, which for a real engine means increased load.

\subsection{Operational parameters of the naturally aspirated engine}

In the first stage of development of the engine with additional expansion of the exhaust gases, tests of the engine in the naturally aspirated (NA) version were conducted. Figure 7 shows the charts of selected engine operating parameters as a function of rotational speed. The engine was fueled by a stoichiometric mixture (rel. AFR $=1.0$ ) and worked at wide open throttle (WOT). The ignition timing angle was adjusted to obtain maximum brake torque (MBT).

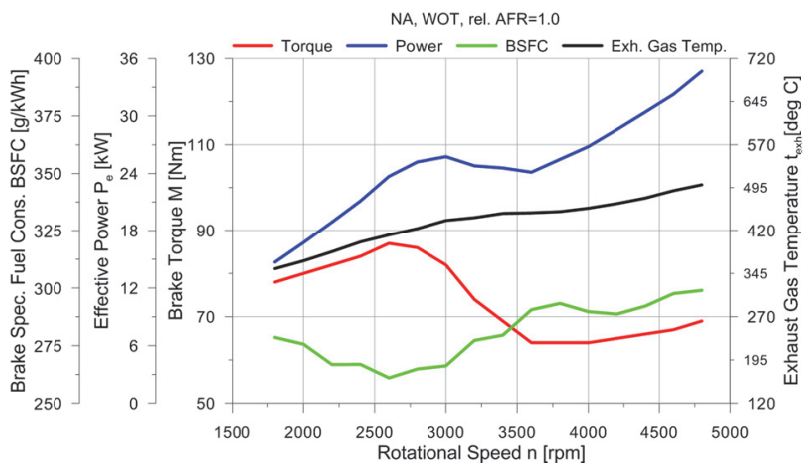

Fig. 7. Operational parameters of the naturally aspirated (NA) engine with an additional expansion process as a function of rotational speed.

During the tests the engine achieved a maximum effective power of $35 \mathrm{~kW}$ at $4800 \mathrm{rpm}$. The tests was not continued for a higher rotational speed because the brake specific fuel consumption (BSFC) has already reached a high level of $300 \mathrm{~g} / \mathrm{kWh}$. The exhaust gas temperature after the extra expansion process is low. During the tests it did not exceed $500{ }^{\circ} \mathrm{C}$. It can be seen in the figure above that, although the maximum value of the torque is relatively high, the torque curve is irregular and different from that encountered for conventional naturally aspirated engines. In order to verify the initial assumptions regarding the explanation of this state, the volumetric efficiency was calculated. Figure 8 shows the curve of the volumetric efficiency as a function of engine speed. The torque curve of the engine has been also showed in this figure to facilitate the analysis.

As it is shown in the figure above, the volumetric efficiency reaches a relatively high maximum value. This is caused by the use of air filter, intake pipe and throttle from the base engine $\left(2.0 \mathrm{dm}^{3}\right.$ of displacement, with turbocharging) but above the rotational speed of $2800 \mathrm{rpm} \eta_{V}$ begins to decrease significantly. This phenomenon may be associated with a disturbed process of exhaust in the engine, in which the exhaust gas after the power stroke does not discharge into the atmosphere, but flows into a next cylinder for further expansion. 


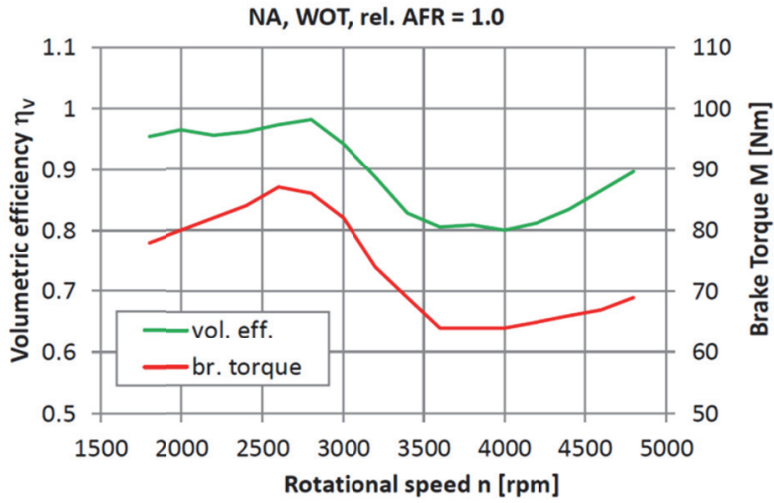

Fig. 8. Volumetric efficiency of the naturally aspirated engine with an additional expansion process.

From a rotational speed of $4200 \mathrm{rpm}, \eta_{V}$ starts to rise slightly again, which in turn can be explained by the occurrence of wave phenomena in the intake manifold pipes with a relatively low length to diameter ratio. The described changes in the course of $\eta_{V}$ as a function of rotational speed are reflected in the brake torque curve of the engine. Minor differences between waveforms of the volumetric efficiency and the brake torque are most likely due to changes in the thermal efficiency and mechanical efficiency of the engine, which was not analyzed at this initial stage of project.

\subsection{Operational parameters of the turbocharged engine with a turbocharger with WG Valve and with a turbocharger with VNT}

The results of the initial tests of the engine in the naturally aspirated version indicated that the minimum BSFC was increased with respect to the original 4-stroke engine, where the best achieved value was slightly below $240 \mathrm{~g} / \mathrm{kWh}$. On the one hand, this is contrary to the aim of the undertaken research work, on the other hand, at the initial stage of the development of the engine in the naturally aspirated version it was an expected phenomenon. The process of additional expansion of the exhaust gases allows to increase the thermal efficiency of the cycle, but one should remember that the mechanical efficiency of the engine, in which in two of four cylinders only additional expansion process takes place, will be undoubtedly lower than for the four-stroke four-cylinder engine.

The five-stroke engine's theoretical cycle exhibits an increase in thermal efficiency along with an increase in the amount of heat supplied, so that, for satisfactory performance, the test engine was equipped with a turbocharger with a boost pressure control by means of waste-gate valve (Fig. 9).

Figure 10 presents selected test results for a turbocharged engine with the turbocharger with the WG valve. The boost pressure $\left(p_{b s t}\right)$ was limited to about 0.35 bar by directly feeding the boost pressure to a pneumatic actuator of the WG valve.

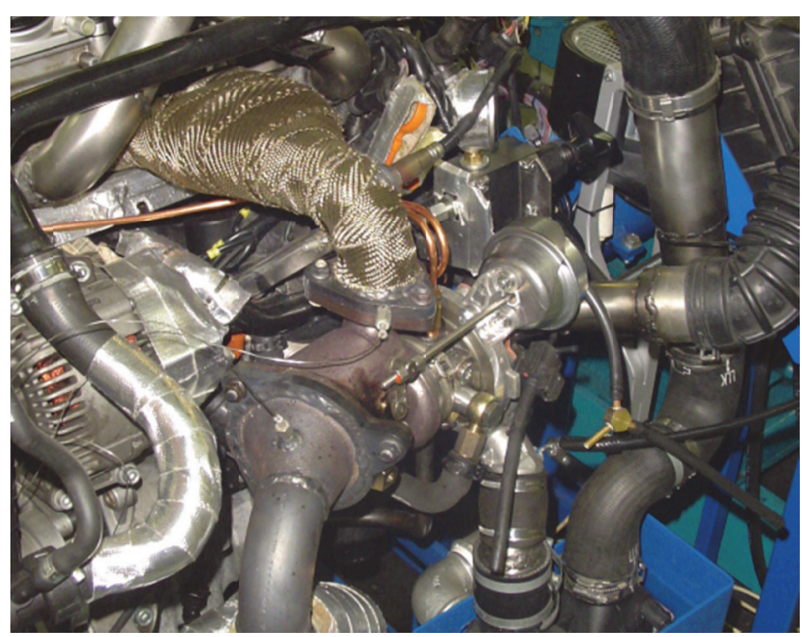

Fig. 9. Turbocharger with a Waste Gate valve mounted on the engine with an additional expansion process.

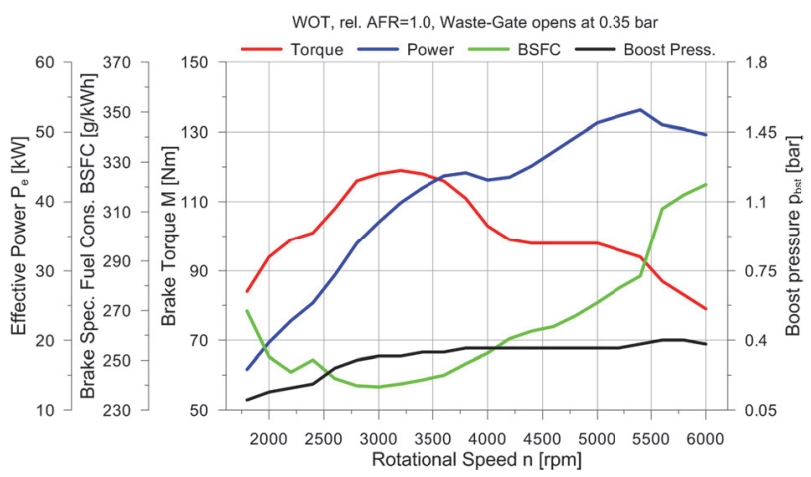

Fig. 10. Operational parameters of the turbocharged engine with an additional expansion process as a function of rotational speed.

Under these conditions, the engine achieved maximum torque of $119 \mathrm{Nm}$ at $3200 \mathrm{rpm}$ and a maximum effective power of $53 \mathrm{~kW}$ at $5400 \mathrm{rpm}$. The minimum BSFC was $239 \mathrm{~g} / \mathrm{kWh}$ at $3000 \mathrm{rpm}$, which is comparable to the best result of the 4-stroke base engine. Above the engine speed of $3600 \mathrm{rpm}$, engine brake torque drastically decreased despite maintaining a constant boost pressure. This is due to the limitation of the engine volumetric efficiency due to the increased flow resistance of exhaust of the engine (Fig. 11).

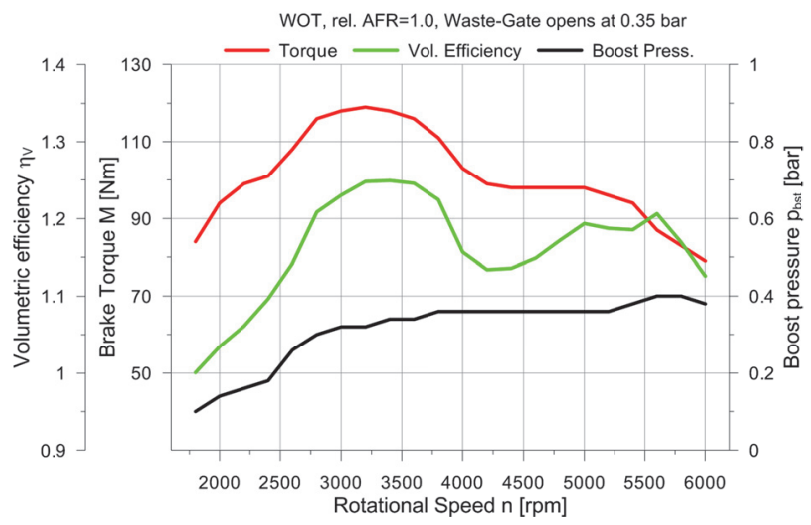

Fig. 11. Volumetric efficiency of the turbocharged engine with an additional expansion process. 
From the rotational speed of $4200 \mathrm{rpm}$, the volumetric efficiency increases again but no increase in the torque is observed. The reason for this is that, similarly to a naturally aspirated engine, the mechanical and thermal efficiency of the engine running at increasing rotational speed decreases.

On the other hand, the turbocharger with WG did not provide the expected boost pressure at low crankshaft rotational speed. The boost pressure of 0.3 bar was reached above the rotational speed of $2800 \mathrm{rpm}$. This meant that the turbocharger did not match the engine characteristics. For this reason, it was decided to investigate how the use of the VNT-type turbocharger would affect performance of the engine with an additional expansion of exhaust gases. After estimating the expected exhaust gas flow it was decided to use the BV35 turbocharger used in CI engines with a displacement of 1.3 and an effective power of about 66 $\mathrm{kW}$. Figure 12 shows a view of a BV 35 turbocharger mounted to the test engine.

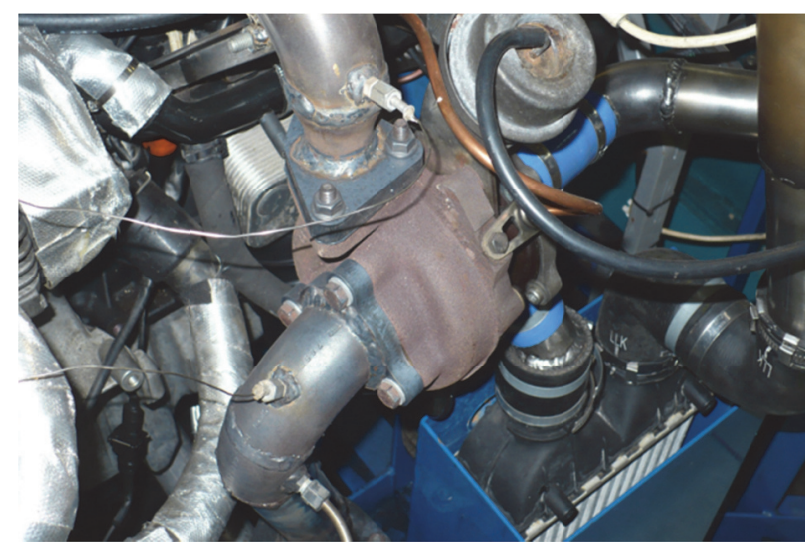

Fig. 12. View of the VNT-type turbocharger mounted to the tested engine.

Figure 13 shows the torque and the BSFC curves as a function of the boost pressure of the test engine running at $2000 \mathrm{rpm}$ and supercharged with a VNT turbocharger. The boost pressure was increased by rotating the turbine nozzle vanes by means of a vacuum actuator.

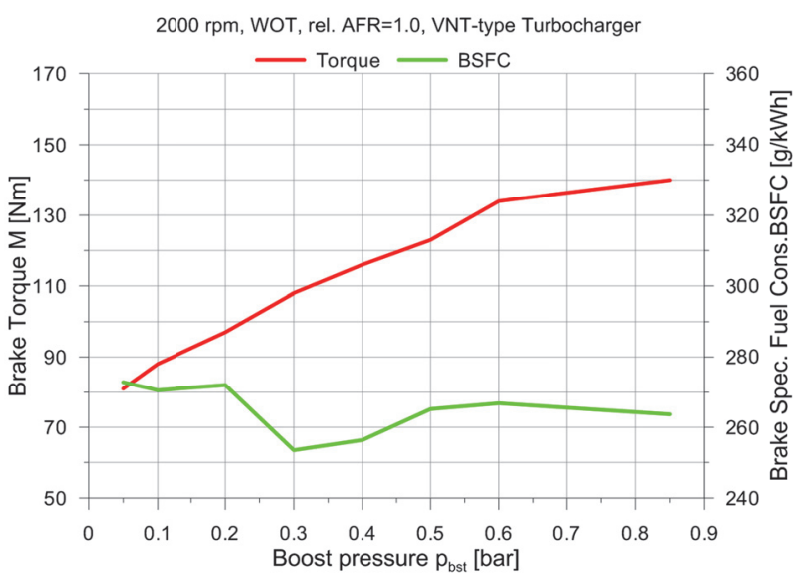

Fig. 13. Brake torque and BSFC as a function of boost pressure of the engine with an additional expansion process working at $2000 \mathrm{rpm}$ with a VNT-type turbocharger.
The maximum torque of $2000 \mathrm{rpm}$ was $140 \mathrm{Nm}$ at $0.85 \mathrm{bar}$, which is a significant increase in comparison to the performance of the engine with a classic turbocharger ( $94 \mathrm{Nm}$ at 0.14 bar). On the other hand, the BSFC is in the entire range higher than that recorded for the engine with a turbocharger with a conventional turbine $(251.4 \mathrm{~g} / \mathrm{kWh}$ at $0.14 \mathrm{bar})$. The minimum value of BSFC with the VNT-type turbocharger was achieved for a boost pressure of $0.3 \mathrm{bar}-253.5 \mathrm{~g} / \mathrm{kWh}$.

Figure 14 shows the torque and the specific fuel consumption curves as a function of the boost pressure $p_{b s t}$ for the engine with additional expansion and with the VNT-type turbocharger. The engine worked this time with a rotational speed of $2800 \mathrm{rpm}$.

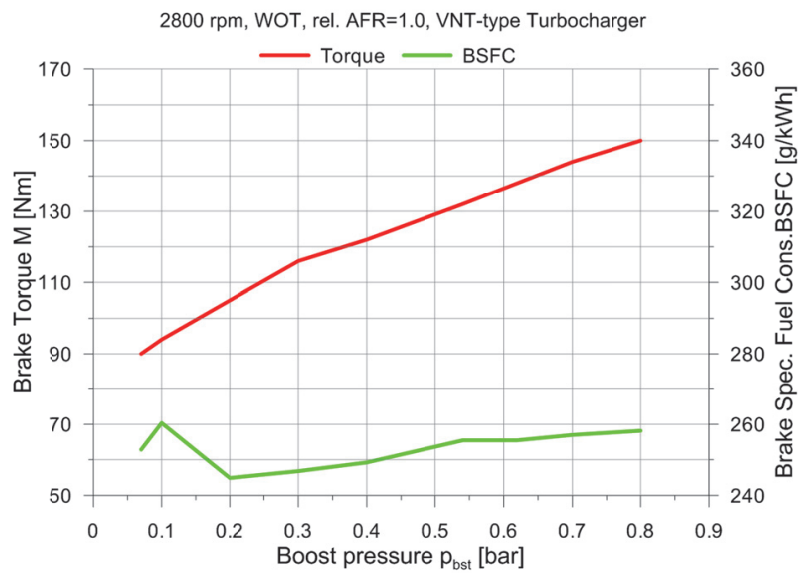

Fig. 14. Brake torque and BSFC as a function of boost pressure of the engine with an additional expansion process working at $2800 \mathrm{rpm}$ with a VNT-type turbocharger.

For a rotational speed of $2800 \mathrm{rpm}$, the situation is similar to that of $2000 \mathrm{rpm}$. The use of the VNT turbocharger allows for a significant increase in boost pressure and, consequently, gives higher engine torque, however, the engine efficiency is reduced again. For the engine equipped with a turbocharger with WG the BSFC of value $239.7 \mathrm{~g} / \mathrm{kWh}$ (at $p_{b s t}=0.3$ bar and $M=116 \mathrm{Nm}$ ) was obtained. With the VNT-type turbocharger, the minimum BSFC was $244.8 \mathrm{~g} / \mathrm{kWh}$ at 0.2 bar of a boost pressure and $105 \mathrm{Nm}$ of torque. For the same torque 116 $\mathrm{Nm}$ as for the turbocharger with $\mathrm{WG}$, the engine had BSFC $246.7 \mathrm{~g} / \mathrm{kWh}$.

The use of the VNT turbocharger allowed to obtain the expected boost pressure even at lower rotational speeds, but the minimum BSFC was higher in both cases than with supercharging by the turbocharger with WG valve. The use of a turbocharger with adjustable nozzle vanes system increases the backpressure of exhaust gases, which in turn has an effect on reducing exhaust gas energy recovery in additional expansion cylinders. In addition, the variable nozzle of a turbine suppresses the effect of the pulsating gas flow into the turbine, which process is not disturbed in a turbocharger with a classic turbine. 


\subsection{Indicated thermal efficiency of the turbocharged engine}

One of the research stages on the developed engine included in-cylinder pressure measurements. The pressure sensors were located in the fired cylinder No. 4 and in the adjacent additional expansion cylinder No. 3 . The research was carried out on a turbocharged engine with WG valve. Measurements were made using Optrand optoelectronic pressure sensors [34].

In the paper [33] an analysis of indicating test results of the engine with additional expansion of exhaust gases is presented. The results of calculating the mechanical efficiency of the engine are presented. The obtained results do not deviate from the only known results available for a five-stroke engine [26]. The maximum value of mechanical efficiency was $85.5 \%$ [33], which is rather lower than that of today's four-stroke engines. The work also outlines the relationship between the power indicated in the fired cylinders and in the additional expansion cylinder assembly and the relationship between the brake mean effective pressure of the engine and the indicated mean effective pressure of the additional expansion cylinders. This allowed to determine the energy recovery rate in the additional expansion cylinders and to determine the load level of the engine from which the additional expansion cylinders deliver power to the engine crankshaft. The results of the analysis indicated that the additional expansion cylinders deliver power to the engine crankshaft at a load of about $60 \mathrm{Nm}$ and higher. Until this value they receive power from the crankshaft, which is due to the fact that, with a low amount of cylinder charge, it is expanded in additional expansion cylinders below ambient pressure (see theoretical cycle). The results of calculating the indicated thermal efficiency of the cycle of engine with additional expansion process will be presented in this paper.

Indicating measurements were carried out at selected points in the engine working area. These points are marked in Figure 15. During testing, the WG valve of the turbocharger was closed in order to obtain maximum performance.

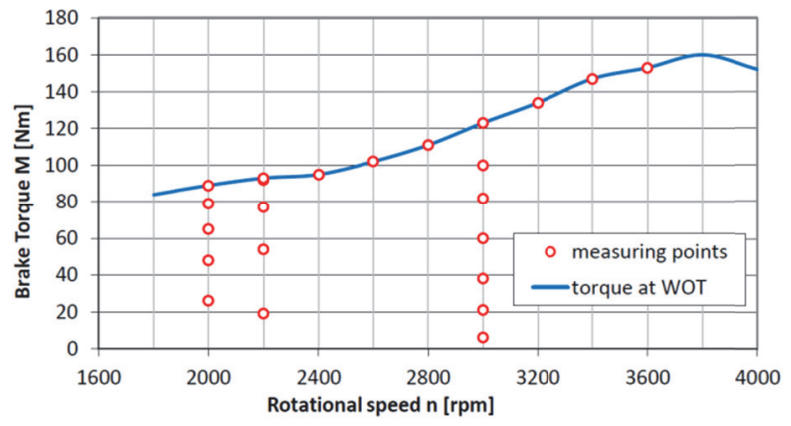

Fig. 15. Points of indicating measurements.

Figure 16 shows an example of the in-cylinder pressure waveforms as a function of crank angle registered for both cylinders at a rotational speed of 2800 $\mathrm{rpm}$ and a load of $111 \mathrm{Nm}$.

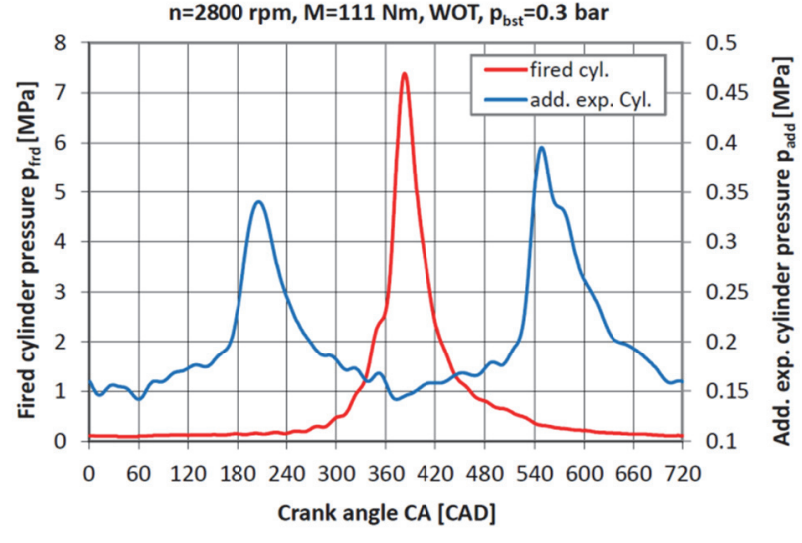

Fig. 16. Indicator diagram of the engine with additional expansion process.

It can be seen in figure above that the pressure course in the additional expansion cylinder No. 3 is not identical for the two presented cycles of this cylinder - covering 360 degrees of the crank angle (CAD). The right part of the chart (360-720 CAD) corresponds to the situation when this cylinder is fed directly from the cylinder No. 4 (red line), while the left part refers to the situation where the exhaust gases flow from the cylinder No. 1 to cylinder No. 2 and then, through the port in the cylinder head feed the cylinder No. 3. The phenomenon of throttling of flow in the port connecting the cylinders No. 2 and 3 explains the difference in the curves of pressure and its maximum value for the additional expansion cylinders. Based on the recorded pressure waveforms obtained as averaged over dozens of cycles, the indicated mean effective pressure (IMEP) was calculated for the fired and additional expansion cylinders. The indicated power was then calculated for both groups of cylinders. It has been taken into consideration that additional expansion occurs in the volume of two cylinders and in the two-stroke mode. Obtaining the indicated power values has allowed to calculate the indicated thermal efficiency of the engine at each measurement point.

For a classical combustion engine, the indicated thermal efficiency can be determined from the formula (9) $[35,36]$ :

$$
\eta_{i}=\frac{P_{i}}{G_{e} \cdot L H V}
$$

where:

$P_{i}$ - indicated power, $\mathrm{kW}$

$G_{e}-$ fuel consumption rate, $\mathrm{g} / \mathrm{s}$

$L H V$ - lower heating value of the fuel, $\mathrm{MJ} / \mathrm{kg}$

For the purposes of this analysis, the value of LHV equal to $43.0 \mathrm{MJ} / \mathrm{kg}$ was assumed. In the case of the engine with an additional exhaust expansion in a separate cylinder, the situation is somewhat different from that of the classic engine. If the engine load is sufficiently high, the exhaust gas recovery takes place in the additional expansion cylinders. In this situation, the indicated mean effective pressure of these cylinders IMEP $_{\text {add }}$ has a value higher than zero. The indicated power of the engine $P_{i_{5} 5 \mathrm{~s}}$ is the sum of the indicated power of the fired cylinders $P_{i_{-} \text {frd }}$ and in the additional 
expansion cylinders $P_{i \text { add }}$. It may also happen that the load on the engine is so low that, in the process of additional expansion, the pressure in these cylinders falls significantly below the exhaust pressure. This is related to the occurrence of the indicated mean effective pressure in the cylinders of additional expansion IMEP $_{\text {add }}$ of a value lower than zero. This means that in the additional expansion cylinders the part of the power resulting from the combustion of the fuel in the fired cylinders is lost. If this is the case, the power indicated in the additional expansion cylinders $P_{i \text { add }}$ of a negative value should be omitted for calculating the indicated thermal efficiency of the cycle $\eta_{i_{5} 5 \mathrm{~s}}$, as these cylinders act then as an inherent load e.g. a water pump or an oil pump in a conventional combustion engine. Naturally, this will lower mechanical efficiency of the five-stroke engine. Equations (10) and (11) show the method of calculating the indicated thermal efficiency of the engine with an additional expansion process considering the above description.

$$
\begin{array}{cc}
\text { for } P_{i_{-} \text {add }}>0: & \eta_{i_{\_} 5 s}=\frac{P_{i_{-} f r d}+P_{i_{\_} a d d}}{G_{e} \cdot L H V} \\
\text { for } P_{i_{\_} \text {add }} \leq 0: & \eta_{i_{-} 5 s}=\frac{P_{i_{\_} f r d}}{G_{e} \cdot L H V}
\end{array}
$$

Figure 17 shows the curves of the indicated thermal efficiency and the effective efficiency (fuel conversion efficiency) of the engine with an additional exhaust gas expansion as a function of the rotational speed at wide open throttle and closed WG valve. Figure 17 also shows the variation of boost pressure and BMEP during the test.

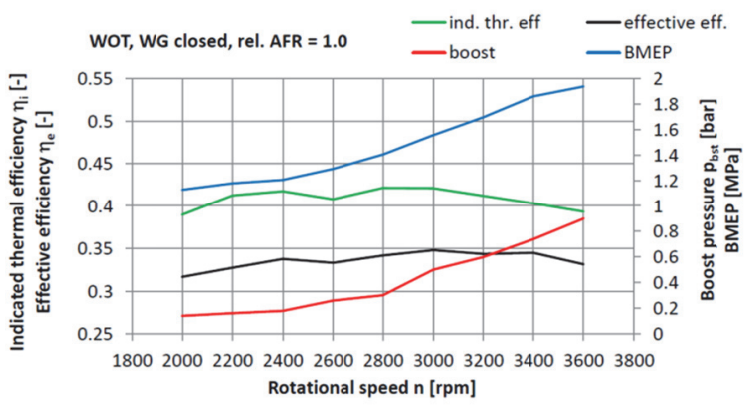

Fig. 17. Indicated thermal efficiency of the engine with an additional expansion process developed at CUT as a function of rotational speed.

The maximum recorded value of the indicated thermal efficiency was approximately 0.42 at 2800-3000 $\mathrm{rpm}$. This is a relatively high value and is the result of an efficient energy recovery process in the additional expansion cylinders. For a rotational speed of $3000 \mathrm{rpm}$, the maximum effective efficiency of the engine operating with the closed WG valve is also recorded.

Figure 18 shows the charts of the indicated thermal efficiency of the engine with the additional expansion of exhaust gases for three constant values of the rotational speed and a variable load.

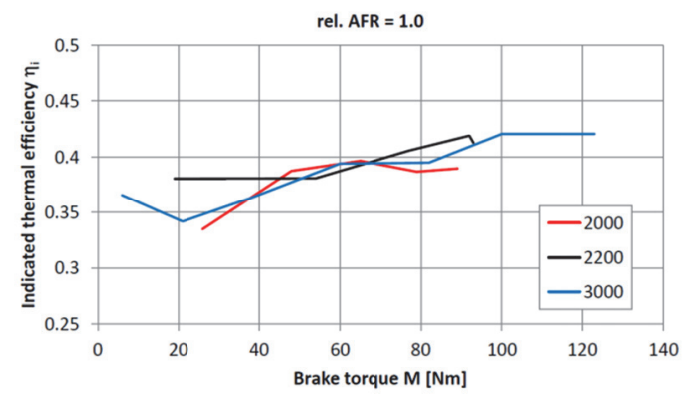

Fig. 18. Indicated thermal efficiency of the engine with the additional expansion process as a function of engine load.

It can be seen that the indicated thermal efficiency increases with the engine load to a maximum value of 0.42 , and also acquires similar values for the various rotational speeds in the analyzed part of the engine operating map.

\section{Conclusions and summary}

On the basis of the results dlescribed in the paper, the author tried to formulate the following detailed conclusions, but also guidelines for further work on the subject:

- For the theoretical cycle of the engine with an additional expansion of exhaust gases, a significantly higher thermal efficiency is obtained than for the Otto cycle. In addition, the efficiency increases with increasing the amount of heat supplied to the cycle. For a real engine, a high indicated thermal efficiency has been achieved, but one should remember that the mechanical efficiency of a five-stroke engine must be lower than for a four-stroke engine. Improving the mechanical efficiency of an existing engine will be difficult. It is possible, for example, to change the method of high fuel pressure control from a relief valve to a supply "on demand" what means that only necessary amount of furel is delivered at high pressure. On the other hand the indicated thermal efficiency may be increased in this engine, what will be described in a detailed form in the next few bullets.

- The engine with additional expansion of the exhaust gases in the naturally aspirated version achieves lower efficiency than the engine in the original fourstroke version. Such a result was generally expected. A participation of friction losses in the naturally aspirated five-stroke engine is so increased (transition from four fired cylinders to two fired and two additional expansion cylinders) that it is not compensated by the exhaust gas energy recovery during extra expansion. In order for the engine with an additional expansion process to operate effectively, it needs to be equipped with a turbocharger. It also follows from the thermodynamic cycle, where the efficiency gain is the higher the higher the amount of heat supplied to the working medium. 
- The use of a turbocharger with the WG valve enabled a significant increase in engine performance and a reduction in the BSFC to a level of the original 4stroke engine, however, the turbocharger did not provide sufficient boost pressure at low engine speeds.

- For the above reason, and because of the low exhaust gas temperature downstream the additional expansion cylinders, it was decided to use the VNT-type turbocharger. Initial tests of this solution have shown that the torque has increased significantly, but the BSFC was increased relative to the situation where the engine worked with the classic turbocharger with a WG valve. This is due to the increased back pressure of the exhaust gas in the additional expansion cylinders caused by the variable nozzle turbine. In the near future, a new turbocharger with a WG valve will be selected with a characteristic for the engine with a displacement of about $1.0 \mathrm{dm}^{3}$, but with exhaust gases of lower energy than that of a conventional engine, due to the additional expansion.

- The indicated thermal efficiency $\eta_{i}$ of the engine with additional exhaust energy recovery is relatively high, is slightly higher than that obtained for the classic four-stroke engine. On the other hand, $\eta_{m}$ is lower, so the effective efficiency $\eta_{e}$ is now similar to that of the classical engine.

- Thermal efficiency would certainly increase thanks to the increasing of the cross section of the port connecting the cylinders No. 2 and No. 3, the reducing the volume of former combustion chamber in cylinders No. 2 and 3 and the shortening of transfer ports between fired and additional expansion cylinders. The simplest method is to increase the port cross-section between the additional expansion cylinders. It would be slightly more difficult to reduce the chambers in additional expansion cylinders by using pistons with higher crown. However, the modification of the transfer ports between the fired and additional expansion cylinders is practically impossible for the cylinder head coming from an existing four-stroke engine.

- It is also planned to optimize the valve timing using the $0 \mathrm{D} / 1 \mathrm{D}$ modeling and simulation. Currently the valve timing is adopted as for the original 4stroke engine, so an improvement of the efficiency of the engine with an additional expansion process is still possible.

- Once the amendments to the existing design have been made, an exhaust gas aftertreatment system will be selected taking into account the specifics of the operation of the engine with an additional expansion (i.e. mainly low temperature downstream the turbine).

The study results show that the five-stroke engine developed at Cracow University of Technology achieves good performance, especially taking into account that it has been developed on the basis of an existing fourstroke engine, what creates some constraints (e.g. two separate cylinders for the additional expansion processes and the cylinder head design). The best results are obtained when working at high load and at about 3000 rpm. The result is that the engine would not be a good source of propulsion for the vehicle with classic drive system, but it will be suitable for applications to vehicles with hybrid drive of series type or extended range electric vehicle, or for stationary applications. A further development of the design is planned in the nearest future to increase the fuel conversion efficiency of the engine while maintaining the stoichiometric air-fuel mixture to allow the use of a simple system of a classic three-way catalytic converter.

\section{References}

1. J. Merkisz, J. Pielecha, S. Radzimirski, Springer Tracts on Transportation and Traffic 4, 1-170 (2014), DOI: 10.1007/978-3-319-02705-0

2. W. Gis, J. Pielecha, J. Waskiewicz, M. Gis, M. Menes, IOP Conference Series-Materials Science and Engineering 148, UNSP 012040 (2016), DOI: 10.1088/1757-899X/148/1/012040

3. L.J. Kapusta, I. Pielecha, K. Wisłocki, A. Teodorczyk, Journal of Thermal Analysis and Calorimetry 123, 819-828 (2016), DOI: $10.1007 / \mathrm{s} 10973-015-4927-\mathrm{z}$

4. P. Staniak, W. Moćko, A. Wojciechowski, Journal of KONES Powertrain and Transport 19, 139-148 (2012)

5. H. Golas, A. Mazur, J. Gruszka, ACSR-Advances in Computer Science Research 57, 257-264 (2016)

6. Z. Juda, Materials Science and Engineering 148, $012043 \quad$ (2016), DOI: $10.1088 / 1757$ 899X/148/1/012043

7. European Commission. Horizon 2020 Work Programme 2016-2017, Smart, green and integrated transport, 91

8. Y. Ota, Y. Ito, A. Kawamura, H. Nishiura, S. Matsuo, Toyota Technical Review 62, 54-59 (2016)

9. G. Koszalka, Eksploatacja i Niezawodnosc Maintenance and Reliability 16, 133-139 (2014)

10. M. Noga, B. Sendyka, International Journal of Automotive Technology 15, 1083-1089 (2014), DOI: $10.1007 / \mathrm{s} 12239-014-0112-9$

11. I. Pielecha, W. Cieslik, Journal of Thermal Analysis and Calorimetry 126, 815-827 (2016), DOI: 10.1007/s10973-016-5544-1

12. I. Pielecha, M. Skowron, W. Bueschke, W. Cieslik, $\mathrm{K}$. Wislocki, IOP Conference Series-Materials Science and Engineering 148, UNSP 012081 (2016), DOI: 10.1088/1757-899X/148/1/012081

13. M. Noga, B. Sendyka, Bulletin of the Polish Academy of Sciences: Technical Sciences 62, 349355 (2014), DOI: 10.2478/bpasts-2014-0034

14. I. Pielecha, Journal of Thermal Analysis and Calorimetry 118, 217-225 (2014), DOI: 10.1007/s10973-014-3956-3

15. C.L. Cummins, Internal Fire (Carnot Press: Wilsonville, 2000) 
16. R.H. Miller, ASME Transactions 69, 453-464 (1947)

17. T. Goto, K. Hatamura, S. Takizawa, N. Hayama, H. Abe, H. Kanesaka, SAE Technical Paper 940198 (1994), DOI: 10.4271/940198

18. S. Harada, T. Shinagawa, T. Kondo, K. Togawa, M. Kudo, W. Matsubara, Toyota Technical Review 62, 54-59 (2016)

19. K. Grab-Rogaliński, S. Szwaja, Combustion Engines 162 (2015)

20. I. Pielecha, J. Czajka, P. Borowski, K. Wisłocki, Combustion Engines 154, 517-524 (2013)

21. I. Pielecha, International Journal of Automotive Technology 15, 47-55 (2014), DOI: 10.1007/s12239-014-0005-y

22. J.B. Heywood, Internal Combustion Engine Fundamentals (Mc Graw-Hill, 1988)

23. V. Gheorghiu, 10th Biennial Conference on Engineering Systems Design and Analysis (2010), DOI: 10.1115/ESDA2010-24031

24. G. Schmitz, US Patent No. 6553977 (2003), http://www.google.com/patents/US6553977 (accessed on 17th of March 2016)

25. C. Ailloud, B. Delaporte, G. Schmitz, A. Keromnes, L. Le Moyne, SAE Technical Paper 2013-24-0095 (2013), DOI: 10.4271/2013-24-0095

26. Kéromnès, A., Delaporte, B., Schmitz, G., Le Moyne, L. Energy Conversion and Management 82, 259-267 (2014), DOI: 10.1016/j.enconman.2014.03.025

27. T. Li, B. Zheng, T. Yin, Energy Conversion and Management 103, 448-458 (2015), DOI: 10.1016/j.enconman.2015.06.078

28. T. Li, B. Wang, B. Zheng, Energy Conversion and Management 123, 140-152 (2016), DOI: 10.1016/j.enconman.2016.06.038

29. A. Melin, D. Kittelson, W. Northrop, SAE Technical Paper 2015-01-1752 (2015), DOI: 10.4271/2015-01-1752

30. M. Palanivendhan, H. Modi, G. Bansal, International Journal of Control Theory and Applications 9, 5855-5862 (2016)

31. K. Stuart, T. Yan, J. Mathias, SAE Technical Paper 2017-01-0633 (2017), DOI: 10.4271/2017-01-0633

32. M. Noga, B. Sendyka, Journal of KONES Powertrain and Transport 20, 239-246 (2013)

33. M. Noga, Applied Sciences 7, 295 (2017), DOI: 10.3390/app7030295

34. M.T. Wlodarczyk, Combustion Engines 151, 3-8 (2012)

35. R. Van Basshuysen, F. Schäfer (eds), Internal Combustion Engine Handbook: Basics, Components, Systems, and Perspectives (SAE International 22, Warrendale, 2004)
36. I. Pielecha, K. Wislocki, P. Borowski, W. Cieslik, Journal of Thermal Analysis and Calorimetry 122, 473-485 (2015), DOI: 10.1007/s10973-015-4735-5 